\title{
Comparison of Enzymatic and Acidic Fractionation of Corn Fiber for Glucose-rich Hydrolysate and Bioethanol Production by Candida boidinii
}

\author{
Anikó Fehér ${ }^{1}$, Soma Bedő1, Csaba Fehér ${ }^{1 *}$ \\ ${ }^{1}$ Biorefinery Research Group, Department of Applied Biotechnology and Food Science, Faculty of Chemical Technology and \\ Biotechnology, Budapest University of Technology and Economics, H-1111 Budapest, Műegyetem rakpart 3, Hungary \\ * Corresponding author, e-mail: feher.csaba@vbk.bme.hu
}

Received: 01 November 2020, Accepted: 18 March 2021, Published online: 18 May 2021

\begin{abstract}
Corn fiber is a by-product of the corn wet milling process and a promising raw material to produce bioethanol in a bio-refinery process. In this study, enzymatic and acidic fractionations of corn fiber were compared with particular attention to produce glucoserich hydrolyzates. The acidic fractionation contained two, sequential, sulphuric acid-catalyzed, hydrolysis steps based on our previous study. In the enzymatic fractionation process, corn fiber was pre-treated by soaking in aqueous ammonia (18.5 \% (w/w) dry matter, $15 \%$ (w/w) ammonia solution, 24 hours) and then hydrolyzed by using Hemicellulase (NS 22002) enzyme cocktail. The cellulose part of the solid residues obtained after the acidic and enzymatic fractionation processes was enzymatically hydrolyzed by using Cellic Ctec 2 and Novozymes 188 (12.5\% (w/w) dry matter, $50{ }^{\circ} \mathrm{C}, 72$ hours). Cellulose hydrolysis after the acidic and enzymatic fractionation resulted in a supernatant containing $64 \mathrm{~g} / \mathrm{L}$ and $25 \mathrm{~g} / \mathrm{L}$ glucose, respectively. Therefore, ethanol fermentation experiments were performed in Separated Hydrolysis and Fermentation (SHF) and Simultaneous Saccharification and Fermentation (SSF) configurations after the acidic fractionation of corn fiber. SHF configuration was found to be more advantageous regarding the achievable ethanol yield. Although the fermentation with Candida boidinii NCAIM Y.01308 was accomplished within longer time (43 hours) compared to Saccharomyces cerevisiae (5 hours), the achieved ethanol yields were similar (79 \%) during the SHF process. It was concluded that acidic fractionation is more efficient to produce glucose-rich hydrolyzate from corn fiber compared to enzymatic fractionation, and Candida boidinii is suitable for ethanol fermentation on the glucose-rich hydrolyzate.
\end{abstract}

\section{Keywords}

biomass, pre-treatment, hydrolysis, ethanol, yeast, biorefinery

\section{Introduction}

Due to the increasing demand of our population for energy and materials there is an urgent need to find renewable resources to replace fossil resources [1]. Lignocellulosic biomass is an abundant, renewable, low-cost feedstock having the potential to be converted into value-added bio-products such as biofuels, chemicals, enzymes, and organic acids [1-7]. Lignocellulosic biomass can be separated into cellulose, hemicellulose, and lignin by different fractionation methods, which generally contain pre-treatment and hydrolysis process steps [8, 9]. One promising pre-treatment method is soaking in aqueous ammonia (SAA) treatment, which opens up the structure of the biomass, partly removes or modifies lignin, and increases the surface area of cellulose and hemicellulose structure [10, 11]. SAA does not generate sugar degradation products, and it can result in a treated material that is highly digestible by enzymes [12]. However, in order to obtain a pre-treated material that is highly accessible for enzymatic degradation, setting the optimal conditions of the SAA treatment (temperature, time, $\mathrm{NH} 4 \mathrm{OH}$ concentration, dry matter content, etc.) is crucial [13]. SAA treatment was found to be a promising pre-treatment method for the valorization of corn fiber (CF) $[12,14]$. CF is one of the co-products of the corn wet milling process and huge amount of that, around $530 \mathrm{~T} /$ day, is produced in Hungary. Its main component is lignocellulose (hemicellulose $35 \%$, cellulose $19 \%$, lignin $8 \%$ ), and it contains significant amount of starch $(23 \%)$ as well $[15,16]$. Although CF is mainly valorized in feeds, it can be also a useful substrate for bioethanol production [17]. Recently, intense research efforts have been 
made to develop novel and efficient processes for the conversion of CF into ethanol, which could highly improve the ethanol yield in a corn-to-ethanol facility [18-21]. In addition, CF could serve as a raw material for the production of other high-value bio-products beside ethanol, if it is utilized in a biorefinery process allowing the efficient and selective fractionation of valuable CF components, such as hemicellulosic sugars. Due to the complex structure of the hemicellulose of CF, it can hardly be enzymatically hydrolyzed into monomer sugars [22, 23], however it is relatively easy to solubilise by dilute acidic hydrolysis [24]. Thus the cellulose content of CF can be sharply separated from the hemicellulose content by dilute acidic treatment [22].

However, dilute acid treatment has many disadvantages compared to the enzymatic deconstruction of the hemicellulose structure of lignocellulosic materials, such as the formation of inhibitor compounds like furfural, 5-hydroxymethylfurfural (HMF), acetic acid and phenolic compounds $[5,25,26]$. To obtain high concentration of hemicellulosic sugars and low concentration of inhibitors during the dilute acidic treatment of lignocellulosic biomass, the operating parameters, such as temperature, reaction time, acid concentration, solid-to-liquid ratio have to be optimized [8, 9, 27]. Among different mineral and organic acids, sulphuric acid has been found as a cheap and efficient catalyst to solubilize hemicellulose content of a lignocellulosic biomass. After pre-treatment and hemicellulose removal from lignocellulosic materials, the remaining cellulose enriched fraction is considered as a promising material for bioethanol production.

During a process of lignocellulosic bioethanol production, enzymatic cellulose hydrolysis and ethanol fermentation can be accomplished by applying different strategies such as Simultaneous Saccharification and Fermentation (SSF) and Separated Hydrolysis and Fermentation (SHF) [28-31]. However, in the literature there is no consensus on that which strategy is more effective. That can depends on several factors (e.g. type of the biomass, pre-treatments, enzymes and microorganisms applied in the process) and both strategies have many advantages and disadvantages [32, 33].

Candida boidinii is a xylose-consuming and methylotrophic yeast that has been mostly used for the production of xylitol [34] and formate dehydrogenase enzyme [35, 36]. However, Gonçalves et. al [37] reported that the novel isolates of $C$. boidinii UFMG14 is also able to produce ethanol. In this report it has been confirmed that even in the presence of inhibitory compounds as furfural, HMF and acetic acid, C. boidinii UFMG14 can produce ethanol on the hydrolysate of Acrocomia aculeate, a Brazilian palm tree, obtained by acidic treatment $(0.8 \%$ (v/v) sulphuric acid, $10 \%$ dry matter, $121{ }^{\circ} \mathrm{C}, 60$ minutes).

The general aim of this study is to select an efficient fractionation process of $\mathrm{CF}$ to enhance ethanol production and to allow the separation of other high value bio-products. Separation of valuable components beside an improved ethanol fermentation process could lead to the complex and sustainable valorization of $\mathrm{CF}$ in a real biorefinery process. Thus, the specified aims of this study are the followings: (1) compare enzymatic and acidic fractionation of CF with particular attention on the glucose concentration available in the final, glucose-rich hydrolysate, and in terms of the other recoverable compounds; (2) investigate the ethanol production on the glucose-rich hydrolysate by using C. boidinni NCAIM Y.01308; (3) compare SHF and SSF configurations in terms of the achievable ethanol yield and productivity.

\section{Materials and methods}

\subsection{Corn fiber}

Corn fibrer (CF) was kindly donated by Hungrana Starch and Isosugar Manufacturing and Trading Co. Ltd. (Szabadegyháza, Hungary). It was dried and stored at room temperature. The dry matter content of the dried sample was $97 \%(w / w)$.

\subsection{Compositional analysis}

Determination of structural carbohydrates and Klason lignin was accomplished using National Renewable Energy Laboratory (NREL) method with minor modifications [38-40]. A half gram, dry, ground, representative solid sample was mixed with $2.5 \mathrm{~mL}$ of $72 \%$ (w/w) sulphuric acid. The mixture was kept at room temperature for 2 hours and mixed every half hour. After 2 hours, $75 \mathrm{~mL}$ of ultrapure (milli-Q) water was added to the mixture and it was treated for an hour at $120^{\circ} \mathrm{C}$ in autoclave. The mixture was then filtered on G4 glass filter with vacuum. Liquid fraction was analyzed by high-performance liquid chromatography (HPLC) to determine its monosaccharide content. The solid fraction remaining on the G4 glass filter (acid insoluble residue) was washed with distilled water until neutral $\mathrm{pH}$ and then it was measured gravimetrically after an overnight drying at $105^{\circ} \mathrm{C}$. The acid insoluble inorganic compound was measured gravimetrically after a 6-hours incineration of the acid insoluble residue at $550{ }^{\circ} \mathrm{C}$. Klason lignin is equal to the acid insoluble residue minus the acid insoluble inorganic compound. The starch content of CF 
was determined using thermostable $\alpha$-amylase donated by Hungrana Starch and Isosugar Manufacturing and Trading Co. Ltd. Dry, ground sample of CF was suspended in a sodium acetate buffer $(\mathrm{pH} 4.8,100 \mathrm{mM})$ at $3 \%(\mathrm{w} / \mathrm{w})$ dry matter content, and then treated with $\alpha$-amylase $\left(2400 \mathrm{U} / \mathrm{kg}\right.$ dry matter) in 1-L closed glass-flasks at $90{ }^{\circ} \mathrm{C}$ for 3 hours with continuous agitation $(250 \mathrm{rpm})$ in a water bath. The supernatant was separated by vacuum filtration through a nylon filter $(150 \mu \mathrm{m})$, mixed with $8 \%(\mathrm{w} / \mathrm{w})$ sulphuric acid at a volume ratio of $1: 1$, and treated at $120{ }^{\circ} \mathrm{C}$ in an autoclave for 15 minutes to decompose oligosaccharides. The monosaccharide content was analyzed by HPLC.

\subsection{Soaking in aqueous ammonia (SAA) treatment}

Soaking in aqueous ammonia (SAA) treatment of CF was performed using the method of Nghiem et al. [12] with minor modifications. The SAA treatment of CF was performed at $18.5 \%(\mathrm{w} / \mathrm{w})$ dry matter content using a $20 \%(\mathrm{w} / \mathrm{w})$ ammonia solution for 7.4 hours or at $18.5 \%(\mathrm{w} / \mathrm{w})$ dry matter content using a $15 \%(\mathrm{w} / \mathrm{w})$ ammonia solution for 24 hours. The obtained solid fractions are referred to as corn fiber treated by soaking in aqueous ammonia for 7.4 hours (CFSAA7.4) and corn fiber treated by soaking in aqueous ammonia for 24 hours (CFSAA24) (Fig. 1). SAA treatments were carried out at room temperature in closed glass-flasks in a rotary shaker $(175 \mathrm{rpm})$. The solid fraction was separated by vacuum filtration through a nylon filter $(150 \mu \mathrm{m})$, washed with distilled water $\left(80^{\circ} \mathrm{C}\right)$ until neutral $\mathrm{pH}$. The supernatant was analyzed by HPLC.

\subsection{Two-step acidic fractionation of corn fiber}

The two-step acidic fractionation process of $\mathrm{CF}$ was performed using the method of Fehér et. al. [14], which includes two sequential hydrolyses catalyzed by sulphuric acid. The conditions of the first and second acidic hydrolyses are summarized in Table 1. The two-step acidic fractionation of $\mathrm{CF}$ results in an arabinose- and glucose-rich supernatant in the first step, and a xylose-rich supernatant and cellulose-rich solid fraction in the second step [14]. The cellulose-rich solid fraction obtained in our study is named as acidic fractionated corn fiber (AFCF) (Fig. 1).

\subsection{Enzymatic hemicellulose hydrolysis}

Enzymatic hemicellulose hydrolysis was performed on SAA treated CF (CFSAA7.4 and CFSAA24) in sodium acetate buffer ( $\mathrm{pH} 5.0,100 \mathrm{mM}$ ) for 72 hours at $50{ }^{\circ} \mathrm{C}$ and $180 \mathrm{rpm}$ (Fig. 1). The dry matter content was $10 \%(\mathrm{w} / \mathrm{w})$ and $0.02 \mathrm{~g}$ Hemicellulase (NS 22002, Novozymes A/S, Bagsvaerd, Denmark) enzyme preparation per gram of dry matter was applied. The Hemicellulase had fungal $\beta$-glucanase activity of $45 \mathrm{U} / \mathrm{g}$ enzyme preparation and fungal xylanase activity of $470 \mathrm{U} / \mathrm{g}$ enzyme preparation, according to its data sheet [41]. The solid fraction obtained in the enzymatic

Table 1 Conditions of the two-step acidic fractionation of corn fiber

\begin{tabular}{lcc}
\hline & \multicolumn{1}{c}{$\begin{array}{c}\text { First } \\
\text { acidic hydrolysis }\end{array}$} & $\begin{array}{c}\text { Second } \\
\text { acidic hydrolysis }\end{array}$ \\
\hline $\begin{array}{l}\text { Temperature }\left({ }^{\circ} \mathrm{C}\right) \\
\text { Time (min) }\end{array}$ & 90 & 120 \\
$\begin{array}{l}\text { Dry matter } \\
(\%, w / w)\end{array}$ & $30^{*}$ \\
$\begin{array}{l}\text { Sulphuric acid } \\
(\%, \text { w } / \text { w) }\end{array}$ & 10 & 10 \\
$\begin{array}{l}\text { Device } \\
\text { Separation }\end{array}$ & water bath \\
Other & solid fraction was washed for neutral pH and \\
& dried at $40^{\circ} \mathrm{C}$
\end{tabular}

* Plus a heating period of 15 minutes and a cooling period of 5 minutes in the water bath, and a heating period of 20 minutes and a cooling period of 30 minutes in the autoclave.

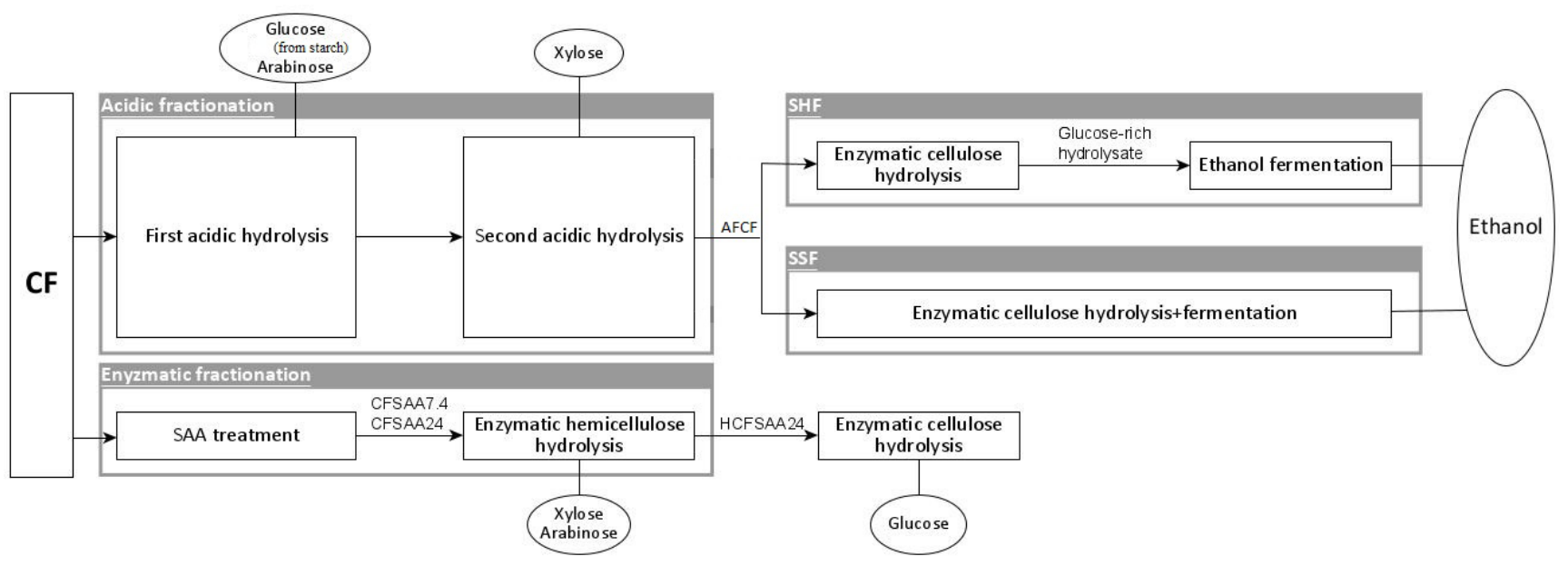

Fig. 1 Outline of the process steps investigated in this study 
hemicellulose hydrolysis of CFSAA24 is referred to as hemicellulose-hydrolyzed corn fiber treated by soaking in aqueous ammonia for 24 hours (HCFSAA24) (Fig. 1).

\subsection{Enzymatic cellulose hydrolysis}

Enzymatic cellulose hydrolysis was carried out on AFCF and HCFSAA24 (Fig. 1) in sodium acetate buffer $(100 \mathrm{mM}$, $\mathrm{pH} 5.0)$ at $12.5 \%(\mathrm{w} / \mathrm{w})$ dry matter with $0.03 \mathrm{~g}$ Cellic Ctec2 (CC2, Novozymes A/S, Bagsvaerd, Denmark) enzyme preparation per gram of dry matter at $50^{\circ} \mathrm{C}$ and $180 \mathrm{rpm}$ for 72 hours. This enzyme dosage corresponded to $2.3 \mathrm{FPU} / \mathrm{g}$ dry matter. CC2 is a cellulase enzyme complex developed for the efficient degradation of cellulose to fermentable sugars. This enzyme preparation is a blend of cellulase, $\beta$-glucosidase and hemicellulase. Cellulase activity of $\mathrm{CC} 2$ was determined at both $50^{\circ} \mathrm{C}$ and $30^{\circ} \mathrm{C}$, according to the method described by Ghose [42], and it was expressed in filter paper unit (FPU)/mL. One unit of FPU was defined as the amount of the enzyme releasing $1 \mu \mathrm{mol}$ glucose per minute under the assay condition. $\mathrm{CC} 2$ had cellulase activities of $47.9 \mathrm{FPU} / \mathrm{mL}$ and $117.5 \mathrm{FPU} / \mathrm{mL}$ at $30^{\circ} \mathrm{C}$ and $50^{\circ} \mathrm{C}$, respectively. Novozyme 188 (Novozymes A/S, Bagsvaerd, Denmark), a $\beta$-glucosidase enzyme preparation, was added to the suspension at a dosage of $0.006 \mathrm{~g}$ enzyme preparation/g of dry matter in certain cases. This corresponded to an enzyme loading of 3.4 international unit (IU)/g dry matter. The $\beta$-glucosidase activity of Novozymes 188 was determined by using $p$-nitrophenyl- $\beta$ - $D$-glucopyranoside substrate at $30^{\circ} \mathrm{C}$ and $50^{\circ} \mathrm{C}, \mathrm{pH} 4.8$, following the method detailed by Wood and Bhat [43]. Novozymes 188 had $\beta$-glucosidase activity of $135 \mathrm{IU} / \mathrm{mL}$ and $685 \mathrm{IU} / \mathrm{mL}$ at $30{ }^{\circ} \mathrm{C}$ and $50{ }^{\circ} \mathrm{C}$, respectively. In the case of Cellic Ctec2 and Novozymes 188 addition together, the added enzyme mixture was referred to as CC2N. Samples were taken in every 24 hours and centrifuged at 9000 g-force for $5 \mathrm{~min}$ utes. Supernatants were analyzed by HPLC. The obtained solid fraction is referred to as cellulose-hydrolyzed acidic fractionated corn fiber (CHAFCF). The supernatant of the enzymatic cellulose hydrolysis of AFCF by using CC2N is referred to as glucose-rich hydrolysate and it is used in the ethanol fermentation experiments (Fig. 1).

\subsection{Ethanol fermentation}

Batch fermentations were performed by using Candida boidinii NCAIM Y.01308 (NCAIM, Hungary) and Saccharomyces cerevisiae (active culture with $35 \%$ (w/w) dry matter content (Lesaffre, Hungary)).
C. boidinii was maintained on agar slants containing $1 \%(\mathrm{w} / \mathrm{w})$ glucose, $1 \%(\mathrm{w} / \mathrm{w})$ peptone, $0.3 \%(\mathrm{w} / \mathrm{w})$ yeast extract and $2 \%(\mathrm{w} / \mathrm{w})$ agar at room temperature. It was transferred from the agar slants into the inoculum medium (pH 6) containing $10 \mathrm{~g} / \mathrm{L}$ yeast extract, $15 \mathrm{~g} / \mathrm{L} \mathrm{KH} 2 \mathrm{PO} 4$, $1 \mathrm{~g} / \mathrm{L} \mathrm{MgSO} \mathrm{Mg}_{4} \times 7 \mathrm{H}_{2} \mathrm{O}, 3 \mathrm{~g} / \mathrm{L}\left(\mathrm{NH}_{4}\right) 2 \mathrm{HPO}_{4}$ and $30 \mathrm{~g} / \mathrm{L}$ xylose to prepare a culture for the inoculation of fermentation experiments [44]. The cultivation was performed in $750 \mathrm{~mL}$ Erlenmeyer flasks containing $100 \mathrm{~mL}$ inoculum medium. Then, $C$. boidinii cells were separated by centrifugation (6000 g-force, 15 minutes) and were used to inoculate the fermentation medium. The initial cell concentration of the fermentations was set to $5 \mathrm{~g}$ dry cell weight/L.

In the cases when $S$. cerevisiae was used, the active S. cerevisiae culture was added directly to the fermentation medium to get an initial cell concentration of $5 \mathrm{~g}$ dry cell weight/L.

The fermentations, both with C. boidinni and S. cerevisiae, were carried out at $30^{\circ} \mathrm{C}$ and $\mathrm{pH} 4.8$ under anaerobic conditions in SHF and SSF configurations. The cultures were stirred with magnetic stirring at $250 \mathrm{rpm}$. In SHF configuration, enzymatic cellulose hydrolysis was performed on AFCF with CC2N at $50{ }^{\circ} \mathrm{C}$ for 48 hours prior the fermentation. The enzyme dosages of $\mathrm{CC} 2$ and Novozymes 188 were $0.03 \mathrm{~g} / \mathrm{g}$ dry matter and $0.006 \mathrm{~g} / \mathrm{g}$ dry matter corresponding to $2.3 \mathrm{FPU} / \mathrm{g}$ dry matter and $3.4 \mathrm{IU} / \mathrm{g}$ dry matter, respectively. Then fermentations were accomplished on the glucose-rich hydrolysate at $30^{\circ} \mathrm{C}$ (Fig. 1). In SSF configuration, enzymatic cellulose hydrolysis on AFCF by using $\mathrm{CC} 2 \mathrm{~N}$ and ethanol fermentation were occurred simultaneously at $30{ }^{\circ} \mathrm{C}$ (Fig. 1). The enzyme loadings of $\mathrm{CC} 2$ and Novozymes 188 were $0.03 \mathrm{~g} / \mathrm{g}$ dry matter and $0.006 \mathrm{~g} / \mathrm{g}$ dry matter corresponding to $1 \mathrm{FPU} / \mathrm{g}$ dry matter and $0.7 \mathrm{IU} / \mathrm{g}$ dry matter, respectively.

The fermentations were followed by measuring the production of $\mathrm{CO}_{2}$ by an online fermentation monitoring system developed by M. Gyalai-Korpos et al. [45]. At the end of the fermentations, when the $\mathrm{CO}_{2}$ production stopped, samples were taken from the broths. Samples were centrifuged at $9000 \mathrm{~g}$-force for 5 minutes to separate the solid fraction and the supernatant. Glucose, xylose, arabinose, and ethanol concentrations were determined from the supernatants by HPLC.

The schematic diagram of the experiments is shown in Fig. 1. 


\subsection{Determination of total solubilized sugars}

Total solubilized sugars include both the solubilized monosaccharides and oligosaccharides. Total solubilized sugars were determined from the liquid samples of the two-step acidic fractionation, SAA pre-treatments, hemicellulose hydrolyses, and cellulose hydrolyses. To determine the concentration of the total solubilized glucose, xylose, and arabinose, liquid samples were mixed with $8 \%(\mathrm{w} / \mathrm{w})$ sulphuric acid at a volume ratio of $1: 1$, and treated at $120^{\circ} \mathrm{C}$ in autoclave for 15 minutes to hydrolyze oligomer sugars into monomer sugars. Glucose, xylose, and arabinose concentrations of the treated samples were determined by HPLC. In this study, all the sugar concentrations are given as total solubilized sugar concentration.

\subsection{HPLC analysis}

Glucose, xylose, arabinose, and ethanol concentrations were determined by using an HPLC system (LC-10A VP, Shimadzu, Kyoto, Japan) equipped with BioRad (Hercules, CA, USA) Aminex HPX-87H column $(300 \times 7.8 \mathrm{~mm})$ and Micro-Guard Cation $\mathrm{H}+$ Refill Cartridge $(30 \times 4.6 \mathrm{~mm})$ pre-column. The column temperature was set to $65^{\circ} \mathrm{C}$. Isocratic elution with $5 \mathrm{mM}$ sulphuric acid was used at a flow rate of $0.5 \mathrm{~mL} / \mathrm{min}$. The injection volume was $40 \mu \mathrm{L}$. Monosaccharides and ethanol were detected and quantified by refractive index detector. Concentrations were determined by using calibration curves. Standard solutions (10 g/L, $5 \mathrm{~g} / \mathrm{L}, 2.5 \mathrm{~g} / \mathrm{L}, 1.25 \mathrm{~g} / \mathrm{L}, 0.625 \mathrm{~g} / \mathrm{L}$, and $0.3125 \mathrm{~g} / \mathrm{L})$ of glucose, xylose, arabinose, and ethanol were used for the calibration curves.

\subsection{Statistical analysis}

Statistical evaluation was carried out using the software Statistica 12 (Statsoft Inc., Tulsa, OK). Two mean values were compared by performing independent two-tailed $t$-tests. The probabilities are denoted by $p$.

\section{Results and discussion}

\subsection{Effects of the different treatments on the structural carbohydrate and lignin composition}

CF contained $16 \%$ starch, $20 \%$ cellulose, $27 \%$ xylan, $15 \%$ arabinan and $8 \%$ Klason lignin, regarding dry matter. This composition shows a good agreement with previous studies [46, 47]. After the first step of the two-step acidic fractionation process, the solid residue contained $40 \%$ cellulose, $27 \%$ xylan, and $7 \%$ arabinan. During the first acidic hydrolysis, the starch fraction and significant part of the arabinose content were removed from the solid fraction, as these components can be easily hydrolyzed under mild acidic treatments. Other components (e.g., proteins) might also be partly solubilized during the first acidic hydrolysis, resulting in a solid residue that has two times higher cellulose content than CF. In the second step of the two-step acidic fractionation process, most of the xylan and arabinan were solubilized resulting in a solid residue (AFCF) with $52 \%$ cellulose, $7 \%$ xylan, and $1 \%$ arabinan. This second acidic hydrolysis further increased the cellulose content by $12 \%$. These results show a good agreement with the data published by Fehér et al. [14], where the second acidic hydrolysis resulted in a cellulose-rich solid fraction containing $50 \%$ cellulose based on dry weight. Because of the high cellulose content, AFCF seems to be promising for ethanol production.

In the case of SAA treatment, two conditions were tested. The solid residue after soaking in $20 \%$ (w/w) ammonia solution for 7.4 hours (CFSAA7.4) contained $19 \%$ glucan, $27 \%$ xylan, $15 \%$ arabinan, and $8 \%$ Klason lignin, regarding dry matter. The relative xylan, arabinan, and Klason lignin content of CFSAA7.4 is similar to that of CF. However, the ammonia treatment using $15 \%$ (w/w) ammonia solution for 24 hours significantly increased the relative carbohydrate content as the remaining solid fraction (CFSAA24) contained $30 \%$ glucan, $35 \%$ xylan, and $20 \%$ arabinan. The relative Klason lignin content of CFSAA24 was significantly lower (5\% regarding dry matter) than that of CF. Nghiem et al. [12] investigated the SAA treatment (solid to liquid ratio of $1: 11,15 \%(\mathrm{w} / \mathrm{w}) \mathrm{NH} 4 \mathrm{OH}, 65^{\circ} \mathrm{C}$, 8 hours) on destarched CF. Compared to our results, they achieved higher relative glucan (49.7\%) but lower relative xylan content $(26 \%)$. The differences could be explained by the different composition of the raw materials and by the different reaction conditions applied.

Our results, in accord with other studies $[12,48]$, confirmed that SAA treatment has a high retention for the carbohydrate fractions and it is suitable to decrease the lignin content of CF.

\subsection{Enzymatic hemicellulose hydrolysis on CFSAA7.4 and CFSAA24}

CF was treated by SAA to enhance the enzymatic digestibility due to the disruption and swelling of the lignocellulose structure [49, 50].

The efficiency of the SAA treatments was evaluated by performing enzymatic hydrolysis experiments aiming the solubilization of the hemicellulose fraction. To hydrolyze the hemicellulose fraction, Hemicellulase (NS 22002, 
Novozymes A/S) enzyme preparation was applied. Sugar yields were calculated based on the composition of the solid fraction that is derived from the previous process step. The enzymatic hemicellulose hydrolysis on CFSAA7.4 resulted in $16.5 \%$ glucose yield, $37.5 \%$ xylose yield, and $54.7 \%$ arabinose yield after 72 hours. In the case of CFSAA24, the glucose yield was slightly lower (13.1\%), but the xylose $(61.8 \%)$ and arabinose $(76.9 \%)$ yields significantly increased. The enzymatic hemicellulose hydrolysis on CFSAA24 resulted in more than $20 \%$ higher xylose and arabinose yields compared to CFSAA7.4. The reason of the higher xylose and arabinose yields after enzymatic hemicellulose hydrolysis on CFSAA24 might be that CFSAA24 has significantly lower Klason lignin content than CFSAA7.4, thereby facilitating the enzymatic degradability. Thus, SAA treatment of CF for 24 hours with $15 \%(\mathrm{w} / \mathrm{w})$ ammonia solution was more efficient in enhancing the enzymatic digestibility than SAA treatment for 7.4 hours with $20 \%(\mathrm{w} / \mathrm{w})$ ammonia solution.

The glucose, xylose, and arabinose concentrations in the hydrolysate obtained from CFSAA7.4 were $3.0 \mathrm{~g} / \mathrm{L}$, $10.4 \mathrm{~g} / \mathrm{L}$, and $8.0 \mathrm{~g} / \mathrm{L}$, respectively. In contrast, enzymatic hemicellulose hydrolysis on CFSAA24 resulted in more than two times higher concentrations of xylose $(24 \mathrm{~g} / \mathrm{L})$ and arabinose $(16.2 \mathrm{~g} / \mathrm{L})$, but almost the same amount of glucose $(4.5 \mathrm{~g} / \mathrm{L})$. The higher xylan and arabinan content of CFSAA24 together with the increased enzymatic digestibility ( $20 \%$ higher sugar yields achievable) explains the high difference in the obtained sugar concentrations. However, the glucose concentrations achieved were nearly the same in both cases.

The profile of the enzymatic hemicellulose hydrolysis on CFSAA24 is shown in Fig. 2. Most of the hemicellulose sugars were solubilized within 24 hours. After that, only a slight increase was observed in the sugar yields. The glucose, xylose, and arabinose concentrations in the hydrolysate after 24 hours of enzymatic hemicellulose hydrolysis were $3.5 \mathrm{~g} / \mathrm{L}, 22.6 \mathrm{~g} / \mathrm{L}$, and $16.1 \mathrm{~g} / \mathrm{L}$, respectively. It shows that 24 hours of the enzymatic hydrolysis of CFSAA24 is appropriate to release most of the hemicellulose content. Thus, the hemicellulose hydrolysis on CFSAA24 was performed for only 24 hours in the following experiments.

The remaining solid fraction of the enzymatic hemicellulose hydrolysis (HCFSAA24) contained $35 \%$ glucan, $23 \%$ xylan, $10 \%$ arabinan, and $10 \%$ Klason lignin. The relative xylan and arabinan content of HCFSAA24 significantly decreased compared to that of CFSAA24, meanwhile the relative glucan content significantly increased.
However, the relative glucan content of HCFSAA24 is considerably lower than that of AFCF, indicating that the acidic process is more efficient in producing a glucan-rich solid fraction.

\subsection{Enzymatic cellulose hydrolysis on HCFSAA24}

Enzymatic cellulose hydrolysis was performed on HCFSAA24 in order to produce a liquid fraction with high glucose concentration, since the main component of HCFSAA24 is cellulose ( $35 \%$ of the dry matter). The cellulose hydrolysis was performed by using Cellic CTec2 (CC2) or by using the mixture of CC2 and Novozyme 188 enzyme cocktails (CC2N). Sugar yields obtained during the enzymatic cellulose hydrolysis of HCFSAA24 are shown in Table 2.

The HCFSAA24 samples were dried and stored until the cellulose hydrolysis experiments or they were used in wet form immediately. In order to investigate the possible effect

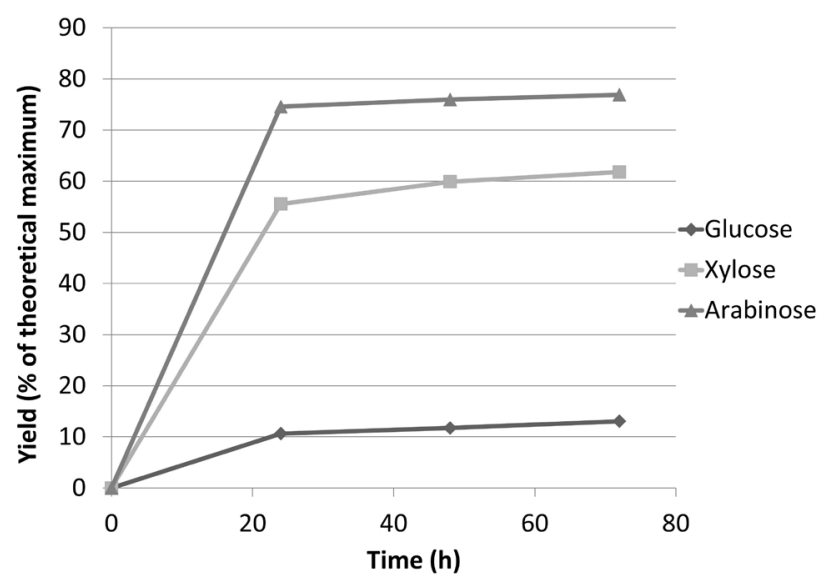

Fig. 2 Sugar yields of enzymatic hemicellulose hydrolysis on corn fiber treated by soaking in aqueous ammonia for 24 hours (CFSAA24)

Table 2 Sugar yields after enzymatic cellulose hydrolysis on HCFSAA24

\begin{tabular}{lcccc}
\hline & & \multicolumn{3}{c}{ Yield (\% of theoretical maximum) } \\
& & Glucose & Xylose & Arabinose \\
\hline 1. & $\mathrm{CC} 2$ & $41.3(2.2)$ & $55.1(2.8)$ & $54.2(3.1)$ \\
2. & $\mathrm{CC} 2 \mathrm{~N}$ & $44.7(0.2)$ & $51.8(2.6)$ & $60.2(2.9)$ \\
3. & CC2 & $46.5(4.5)$ & $68.3(9.7)$ & $73.4(5.4)$ \\
& $($ dried HCFSAA24) & & & \\
4. & CC2N & $51.6(0.9)$ & $67.0(6.7)$ & $70.6(7.5)$ \\
\hline
\end{tabular}

Note: Standard deviations are calculated from triplicates and indicated in parenthesis.

Abbreviations: HCFSAA24- Hemicellulose-hydrolyzed corn fiber treated by soaking in aqueous ammonia for 24 hours

$\mathrm{CC} 2$ - Cellic CTec2

CC2N - Cellic CTec 2 and Novozymes 188 
of using dried or wet samples on the efficiency of cellulose hydrolysis, the glucose yields obtained by using dried or wet samples were compared (Table 2). Significant difference was not observed between the glucose yields achieved on dried or wet samples during the enzymatic hydrolysis with $\mathrm{CC} 2$ ( $p=0.1$, line 1 compared to line 3 in Table 2$)$ or CC2N ( $p=0.3$, line 2 compared to line 4 in Table 2 ).

The effect of adding Novozymes 188 to $\mathrm{CC} 2$ on the achievable glucose yield was also examined. According to the statistical analysis, there was no significant difference between the cases of using $\mathrm{CC} 2$ or $\mathrm{CC} 2 \mathrm{~N}$ enzyme mixtures ( $p=0.1$ when line 1 . is compared to 2 ., and $p=0.4$ when line 3 is compared to 4 . in Table 2).

The profile of liberated sugar concentrations during the cellulose hydrolysis with $\mathrm{CC} 2 \mathrm{~N}$ is shown in Fig. 3. The sugar concentrations continuously increased until the end of the hydrolysis (72 hours). The glucose, xylose, and arabinose concentrations reached $25 \mathrm{~g} / \mathrm{L}, 23 \mathrm{~g} / \mathrm{L}$, and $11 \mathrm{~g} / \mathrm{L}$, respectively (Fig. 3).

In the following experiments, $\mathrm{CC} 2 \mathrm{~N}$ enzyme cocktail was applied in the process step of enzymatic cellulose hydrolysis.

\subsection{Enzymatic cellulose hydrolysis on AFCF}

Enzymatic cellulose hydrolysis experiments were also investigated on the solid fraction produced by the acidic fractionation process (AFCF). Cellulose hydrolysis on AFCF resulted in a liquid fraction containing $64 \mathrm{~g} / \mathrm{L}$ glucose, which corresponds to the glucose yield of $86.2 \%$ of theoretical (Table 3). The xylose and arabinose concentrations were $3.8 \mathrm{~g} / \mathrm{L}$ and $0.4 \mathrm{~g} / \mathrm{L}$, respectively (Table 3 ).

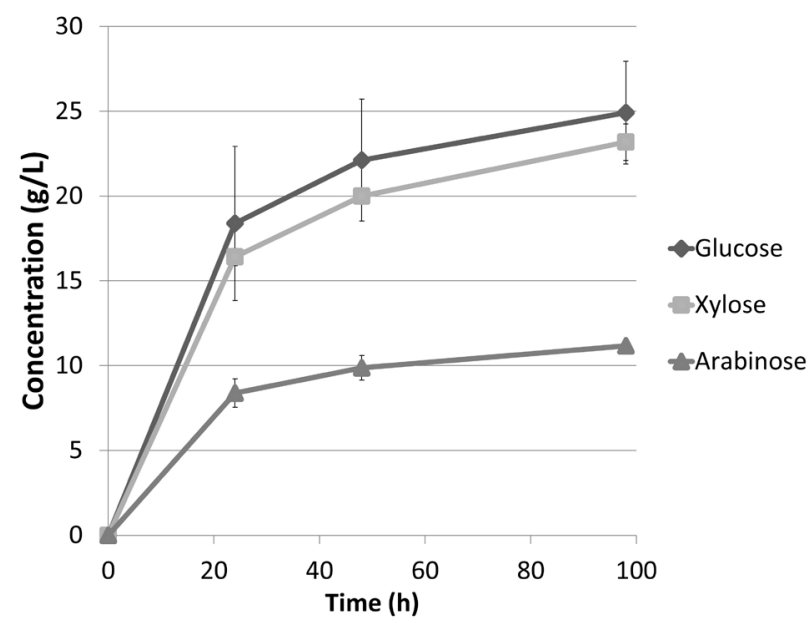

Fig. 3 Sugar concentrations of enzymatic cellulose hydrolysis on hemicellulose-hydrolysed corn fibre treated by soaking in aqueous ammonia for 24 hours (HCFSAA24) by using Cellic CTec 2 and Novozymes $188(\mathrm{CC} 2 \mathrm{~N})$ enzyme mixture
Table 3 Comparison of sugar yields and concentrations achieved during enzymatic cellulose hydrolysis on two-step acidic fractionated corn fiber (AFCF) and hemicellulose-hydrolyzed corn fiber treated by soaking in aqueous ammonia for 24 hours (HCFSAA24).

\begin{tabular}{lccc}
\hline & Glucose & Xylose & Arabinose \\
\hline \multirow{2}{*}{ Yield (\% of theoretical maximum) } \\
AFCF & $86.2(0.6)$ & $32.7(1.1)$ & $27.1(2.2)$ \\
HCFSAA24 & $51.6(0.9)$ & $67.0(6.7)$ & $70.6(7.5)$ \\
& & Concentration $(\mathrm{g} / \mathrm{L})$ \\
AFCF & $64(0.48)$ & $3.8(0.13)$ & $0.4(0.03)$ \\
HCFSAA24 & $25(3.0)$ & $23(1.0)$ & $11(0.02)$ \\
\hline
\end{tabular}

Note: Standard deviations are calculated from triplicates and indicated in parenthesis.

The glucose concentration continuously increased for 72 hours, meanwhile xylose and arabinose concentrations were slightly increased after 24 hours of the enzymatic hydrolysis (Fig. 4). In contrast, the cellulose hydrolysis on HCFSAA24 resulted in much higher xylose ( $23 \mathrm{~g} / \mathrm{L})$ and arabinose $(11 \mathrm{~g} / \mathrm{L})$ concentrations but significantly lower glucose (25 g/L) concentration (Table 3) in the supernatant. The achievable glucose yield during the cellulose hydrolysis of HCFSAA24 was also significantly lower $(51.6 \%$ of theoretical) than that of obtained in the case of AFCF. Moreover, the cellulose content of AFCF was much higher than that of HCFSAA24. The $35 \%$ difference in the obtained glucose yields is derived from the differences of the composition of HCFSAA24 and AFCF. AFCF has high glucan content and low xlyan and arabinan content, therefore cellulase enzymes can easily access the substrate, resulting in high glucose yield. Thus, acidic fraction followed by enzymatic cellulose hydrolysis was found to be much favorable in terms of producing a liquid fraction that contains glucose in high concentration and other sugars in low concentration.

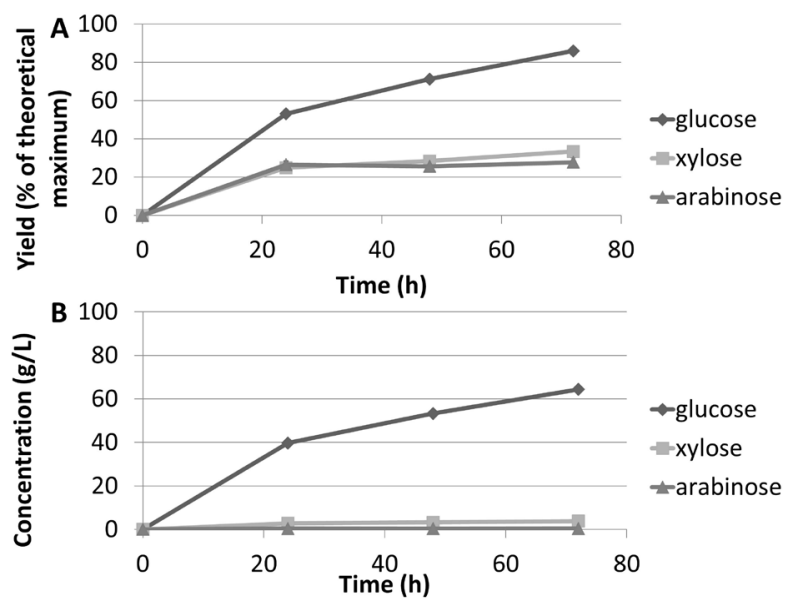

Fig. 4 Sugar yields (A) and concentrations (B) during enzymatic cellulose hydrolysis on AFCF 


\subsection{Ethanol fermentation}

Candida boidinii NCAIM Y.01308 was investigated for its ability to ferment ethanol on the glucose-rich hydrolysate in SHF and SSF configurations, and it was compared with Saccharomyces cerevisiae. Ethanol fermentations were followed by online fermentation monitoring system, which is able to follow the ethanol fermentation $\left(\mathrm{CO}_{2}\right.$ gas production) in real time, delivering an immediate feedback of the process [45]. The real time gas $\left(\mathrm{CO}_{2}\right)$ volume plots showed that in both configurations (SHF, SSF) C. boidinii produced only small amount of $\mathrm{CO}_{2}$ at the beginning (up to 8 hours) of the fermentation (data not shown), suggesting the presence of an adaptation period. This adaptation period might derive from the different composition of the semi-synthetic inoculum medium and the enzymatic hydrolysate of AFCF. The hydrolysate might contain inhibitory compounds which could require an adaptation period if the applied microorganism is sensitive against them. However, after this period, the $\mathrm{CO}_{2}$ production became intensive. In contrast, $S$. cerevisiae started to produce $\mathrm{CO}_{2}$ intensively right after the inoculation. Apart from the adaptation period, $C$. boidinii showed similar gas production profile to $S$. cerevisiae (data not shown). However, the fermentation accomplished much faster in the case of $S$. cerevisiae compared to C. boidinii. In SHF configuration, the ethanol yields were $78.5 \%$ and $79.4 \%$ with $S$. cerevisiae and $C$. boidinii, respectively (Table 4). In SHF process, $S$. cerevisiae and $C$. boidinii produced $\mathrm{CO}_{2}$ until 5 and 43 hours of fermentation, respectively, indicating that $S$. cerevisiae resulted in a faster ethanol production compared to $C$. boidinii. In SSF configuration, the ethanol yields were $60.1 \%$ and $56.0 \%$ with $S$. cerevisiae and C. boidinii, respectively (Table 4).

Table 4 Ethanol fermentation on glucose-rich hydrolysate with Saccharomyces cerevisiae and Candida boidinii

\begin{tabular}{lcccc}
\hline & \multicolumn{2}{c}{$\begin{array}{c}\text { Saccharomyces } \\
\text { cerevisiae }\end{array}$} & \multicolumn{2}{c}{$\begin{array}{c}\text { Candida } \\
\text { boidinii }\end{array}$} \\
& SHF & SSF & SHF & SSF \\
\hline $\begin{array}{l}\text { Ethanol conc. } \\
\text { (g/L) }\end{array}$ & 26.1 & 22.9 & 30.3 & 17.7 \\
Ethanol yield & $(0.5)$ & $(0.6)$ & $(0.01)$ & $(0.5)$ \\
(\% of theoretical maximum) & 78.5 & 60.1 & 79.4 & 56.0 \\
& $(3.1)$ & $(1.7)$ & $(0.01)$ & $(1.4)$ \\
g ethanol from 1 g corn fiber & 0.19 & 0.18 & 0.24 & 0.14 \\
& $(0.03)$ & $(0.01)$ & $(0.01)$ & $(0.04)$ \\
Hydrolysis time (h) & 72 & 107 & 72 & 150 \\
Fermentation time (h) & 5 & & 43 & \\
\hline
\end{tabular}

Note: Standard deviations are calculated from triplicates and indicated in parenthesis.
Thus, ethanol fermentation in SHF configuration on glucose-rich hydrolysate of CF was found to be more efficient in achieving high ethanol yields compared to SSF configuration (Table 4). Our process, including the acidic fractionation of CF, enzymatic hydrolysis of the solid residue of the fractionation and ethanol fermentation on the obtained glucose-rich hydrolysate, resulted in $0.14-0.24 \mathrm{~g}$ ethanol from $1 \mathrm{~g} \mathrm{CF}$ (Table 4). However, due to the two-step acidic fractionation, not only ethanol but other valuable products (arabinose, xylose) could also be obtained in this process.

Van Eylen et al. [46] achieved similar ethanol production (0.159 g ethanol/g CF), when milled CF was treated with dilute sulphuric acid followed by enzymatic hydrolysis with Cellic CTec 2 and $\beta$-glucosidase, and ethanol fermentation by Saccharomyces cerevisiae for 160 hours [46]. However, by using a recombinant strain for xylose and glucose co-fermentation, an ethanol production of $0.286 \mathrm{~g}$ ethanol/g CF was achieved [46]. Myat and Ryu [47] investigated ethanol production from destarched and extruded CF by using Celluclast $1.5 \mathrm{~L}$ and Viscozyme L for saccharification and Saccharomyces cerevisae (ATCC 24858) for xylose and glucose co-fermentation in a configuration called semi-simultaneous saccharification and fermentation. The achieved ethanol concentration $(29.08 \mathrm{~g} / \mathrm{L})$ was similar to that obtained in our study. However, in both previously described cases, ethanol fermentations were supplemented with additional nutrients, which was not necessary in our study. O'Brien et al. [51] reported batch ethanol fermentation with E. coli (strain KO 11) on neutralized hydrolysate derived from dilute sulphuric acid (1\% (w/w) $\mathrm{H}_{2} \mathrm{SO}_{4}, 1 \mathrm{~h}, 121^{\circ} \mathrm{C}$ ) treatment of CF. The fermentations resulted in ethanol yields and ethanol concentrations of $0.32-0.43 \mathrm{~g} / \mathrm{g} \mathrm{CF}$ and $29-44 \mathrm{~g} / \mathrm{L}$, respectively [51]. In this study, neutralization by strongly basic anion exchange was needed to achieve an ethanol concentration similar to ours. Kurambhatti et al. [19] investigated ethanol production on destarched, hot water pre-treated $\left(160{ }^{\circ} \mathrm{C}\right.$, 5-20 minutes) CF, and investigated the effect of the cellulase enzyme dosage on ethanol yields. They achieved $3.36 \mathrm{v} / \mathrm{v} \%$ (around $26.5 \mathrm{~g} / \mathrm{L}$ ) ethanol with SSF configuration under standard fermentation conditions $\left(32{ }^{\circ} \mathrm{C}\right.$, 72 hours, Saccharomyces cerevisiae Ethanol Red, $10 \%$ dry matter) and with a cellulase (Cellic CTec2) loading of $30 \mathrm{FPU} / \mathrm{g} \mathrm{CF}$, after a hot water pre-treatment performed at $160{ }^{\circ} \mathrm{C}$ for 5 minutes [19]. They obtained similar ethanol concentration to that achieved in our study. However, they used much higher cellulase enzyme dosage (30 FPU/g CF) compared to our study (2.3 FPU/g dry matter CC2 and 
$3.4 \mathrm{IU} / \mathrm{g}$ dry matter Novozymes 188 during the SHF process). They also concluded that high CF to ethanol conversion efficiency ( $92.5 \%$ based on total glucose polymers) can be achieved even without pre-treatment if excess cellulase (120 FPU/g CF) was added.

\section{Conclusions}

In our study, enzymatic and acidic fractionations of CF were investigated and compared with particular attention to their efficiency in enhancing the production of a glucose-rich hydrolysate, beside obtaining other valuable fractions. Ethanol production after the acidic fractionation of CF was investigated by using Candida boidinii in SSF and SHF configurations. Based on the two-step acidic fractionation, not only a glucose-rich liquid fraction but other valuable fractions (arabinose, xylose) could be obtained. The glucose-rich hydrolysate obtained by enzymatic cellulose hydrolysis after the acidic fractionation of $\mathrm{CF}$ contained 64 $\mathrm{g} / \mathrm{L}$ glucose. The xylose and arabinose concentrations were low, resulting in a pure glucose solution in terms of carbohydrates. The enzymatic fractionation provided a promising method to solubilize major part of CF hemicellulose under mild process conditions, however, it failed to sharply separate the hemicellulose and cellulose fractions, probably due to the recalcitrant structure of CF hemicellulose. Investigation of novel enzyme cocktails containing wide range of hemicellulose degrading activities would be performed to overcome this obstacle. Therefore, acidic treatment of $\mathrm{CF}$ was found to be more effective to obtain a cellulose-rich solid fraction and thus enhance the production of a glucose-rich hydrolysate compared to SAA treatment combined with enzymatic hemicellulose degradation.

C. boidinii was found to be suitable for ethanol production on the glucose-rich hydrolysate of CF. Moreover, C. boidinii resulted in the same ethanol yield than that of obtained by $S$. cerevisiae. This result provides an additional feature to the diverse applicability of the methylotrophic, xylose-utilizing yeast of C. boidinii. Ethanol fermentation with $C$. boidinii on the glucose-rich hydrolysate resulted in 0.14-0.24 g ethanol/g CF, and SHF configuration was found to be more favorable than SSF in terms of the achieved ethanol yield. Many studies have achieved similar ethanol yields and concentrations to that reported

\section{References}

[1] Chen, H. "1 - Lignicellulose biorefinery engineering: an overview", In: Lignocellulose Biorefinery Engineering, Woodhead Publishing, Cambridge, UK, 2015, pp. 1-17. https://doi.org/10.1016/B978-0-08-100135-6.00001-6 in this study. However, against these studies, in our process neither excess cellulase enzyme dosage, nor nutrients addition was required during the fermentation.

This study concluded that two-step acidic fractionation of $\mathrm{CF}$ is beneficial to produce ethanol from $\mathrm{CF}$, and Candida boidinii NCAIM Y.01308 is a promising yeast for ethanol fermentation.

\section{Acknowledgement}

The authors gratefully acknowledge the projects of TNN_16123305 of the National Research, Development and Innovation Fund of Hungary, the project of VEKOP-2.3.216-2017-00013 supported by the European Union, the State of Hungary and the European Regional Development Fund for their financial support. The research reported in this paper and carried out at BME has been supported by the NRDI Fund (TKP2020 IES, Grant No. BME-IE-BIO) based on the charter of bolster issued by the NRDI Office under the auspices of the Ministry for Innovation and Technology. This article is based upon work from COST Action (CA18229, Yeast4Bio), supported by COST (European Cooperation in Science and Technology, www.cost.eu).

\begin{tabular}{|c|c|}
\hline \multicolumn{2}{|c|}{ Abbreviations } \\
\hline AFCF & Acidic fractionated corn fiber \\
\hline $\mathrm{CC} 2$ & Cellic Ctec2 \\
\hline $\mathrm{CC} 2 \mathrm{~N}$ & Cellic Ctec 2 and Novozymes 188 \\
\hline $\mathrm{CF}$ & Corn fiber \\
\hline CFSAA24 & $\begin{array}{l}\text { Corn fiber treated by soaking in aqueous } \\
\text { ammonia for } 24 \text { hours }\end{array}$ \\
\hline CFSAA7.4 & $\begin{array}{l}\text { Corn fiber treated by soaking in aqueous } \\
\text { ammonia for } 7.4 \text { hours }\end{array}$ \\
\hline CHAFCF & $\begin{array}{l}\text { Cellulose-hydrolyzed, acidic fractionated } \\
\text { corn fiber }\end{array}$ \\
\hline HCFSAA24 & $\begin{array}{l}\text { Hemicellulose-hydrolyzed corn fiber (previ- } \\
\text { ously treated by soaking in aqueous ammo- } \\
\text { nia for } 24 \text { hours) }\end{array}$ \\
\hline HMF & 5-hydroxymethylfurfural \\
\hline HPLC & high-performance liquid chromatography \\
\hline SAA & Soaking in aqueous ammonia \\
\hline SHF & Separated hydrolysis and fermentation \\
\hline SSF & $\begin{array}{l}\text { Simultaneous saccharification and fermen- } \\
\text { tation }\end{array}$ \\
\hline
\end{tabular}

[2] Srivastava, N., Rawat, R., Oberoi, H. S., Ramteke, P. W. "A Review on Fuel Ethanol Production From Lignocellulosic Biomass", International Journal of Green Energy, 12(9), pp. 949-960, 2015. https://oi.org/10.1080/15435075.2014.890104 
[3] Zhang, C. "Lignocellulosic Ethanol: Technology and Economics", In: Yun, Y. (ed.) Alcohol Fuels - Current Technologies and Future Prospect, IntechOpen, London, UK, 2018.

https://doi.org/10.5772/intechopen.86701

[4] Avci, A., Saha, B. C., Dien, B. S., Kennedy, G. J., Cotta, M. A. "Response surface optimization of corn stover pretreatment using dilute phosphoric acid for enzymatic hydrolysis and ethanol production", Bioresource Technology, 130, pp. 603-612, 2013. https://doi.org/10.1016/j.biortech.2012.12.104

[5] Menon, V., Rao, M. "Trends in bioconversion of lignocellulose: Biofuels, platform chemicals \& biorefinery concept", Progress in Energy and Combustion Science, 38(4), pp. 522-550, 2012. https://doi.org/10.1016/j.pecs.2012.02.002

[6] Meneses, D. B., de Oca-Vásquez, G. M. De, Vega-Baudrit, J. R., Rojas-Álvarez, M., Corrales-Castillo, J., Murillo-Araya, L. C. "Pretreatment methods of lignocellulosic wastes into value-added products: recent advances and possibilities", Biomass Conversion and Biorefinery, 2020.

https://oi.org/10.1007/s13399-020-00722-0

[7] Venkatachalam, C. D., Sengottian, M., Ravichandran, S. R., Subramaniyan, K., Thangamuthu, P. K. "Optimization Studies on Subcritical Water Extraction of Fuels and Fine Chemicals from Prosopis juliflora: An Invasive Weed Tree", Periodica Polytechnica Chemical Engineering, 2020.

https://doi.org/https://doi.org/10.3311/PPch.15187

[8] Lee, J. Y., Ryu, H. J., Oh, K. K. "Acid-catalyzed hydrothermal severity on the fractionation of agricultural residues for xyloserich hydrolyzates", Bioresource Technology, 132, pp. 84-90, 2013. https://doi.org/10.1016/j.biortech.2013.01.019

[9] Sarkar, N., Ghosh, S. K., Bannerjee, S., Aikat, K. "Bioethanol production from agricultural wastes: An overview", Renewable Energy, 37(1), pp. 19-27, 2012. https://doi.org/10.1016/j.renene.2011.06.045

[10] Kim, J. S., Lee, Y. Y., Kim, T. H. "A review on alkaline pretreatment technology for bioconversion of lignocellulosic biomass", Bioresource Technology, 199, pp. 42-48, 2016. https://doi.org/10.1016/j.biortech.2015.08.085

[11] Kim, T. H., Gupta, R., Lee, Y. Y. "Pretreatment of Biomass by Aqueous Ammonia for Bioethanol Production", In: Mielenz, J. R. (ed.) Biofuels: Methods and Protocols, Humana Press, Totowa, NJ, USA, 2009, pp. 79-91.

https://doi.org/10.1007/978-1-60761-214-8_6

[12] Nghiem, N. P., Montanti, J., Johnston, D. B., Drapcho, C. "Fractionation of Corn Fiber Treated by Soaking in Aqueous Ammonia (SAA) for Isolation of Hemicellulose B and Production of C5 Sugars by Enzyme Hydrolysis", Applied Biochemistry Biotechnology, 164, pp. 1390-1404. 2011. https://doi.org/10.1007/s12010-011-9220-4

[13] Pryor, S. W., Karki, B., Nahar, N. "Effect of hemicellulase addition during enzymatic hydrolysis of switchgrass pretreated by soaking in aqueousammonia",BioresourceTechnology, 123,pp.620-626,2012. https://doi.org/10.1016/j.biortech.2012.07.040

[14] Fehér, C., Gazsó, Z., Gál, B., Kontra, A., Barta, Z., Réczey, K. "Integrated Process of Arabinose Biopurification and Xylitol Fermentation Based on the Diverse Action of Candida boidinii", Chemical and Biochemical Engineering Quarterly, 29(4), pp. 587-597, 2015.

https://doi.org/10.15255/CABEQ.2014.2145
[15] Gáspár, M., Juhász, T., Szengyel, Z., Réczey, K. "Fractionation and utilisation of corn fibre carbohydrates", Process Biochemistry, 40(3-4), pp. 1183-1188, 2005.

https://doi.org/10.1016/j.procbio.2004.04.004

[16] Gápár, M., Kálmán, G., Réczey, K. "Corn fiber as a raw material for hemicellulose and ethanol production", Process Biochemistry, 42, pp. 1135-1139, 2007.

https://doi.org/10.1016/j.procbio.2007.04.003

[17] Saha, B. C., Dien, B. S., Bothast, R. J. "Fuel Ethanol Production from Corn Fiber Current Status and Technical Prospects", Applied Biochemistry and Biotechnology, Article number: 70, 1998. https://doi.org/10.1007/BF02920129

[18] Li, X., Xu, Z., Yu, J., Huang, H., Jin, M. "In situ pretreatment during distillation improves corn fiber conversion and ethanol yield in the dry mill process", Green Chemistry, 21(5), pp. 1080-1090, 2019. https://doi.org/10.1039/c8gc03447h

[19] Kurambhatti, C. V, Kumar, D., Rausch, K. D., Tumbleson, M. E., Singh, V. "Ethanol Production from Corn Fiber Separated after Liquefaction in the Dry Grind Process", Energies, 11(11), Article number: 2921, 2018.

https://doi.org/10.3390/en11112921

[20] Beri, D., York, W. S., Lynd, L. R., Peña, M. J., Herring, C. D. "Development of a thermophilic coculture for corn fiber conversion to ethanol", Nature Communications, 11, Article number: 1937, 2020.

https://doi.org/10.1038/s41467-020-15704-z

[21] Norvell, K. L., Nghiem, N. P. "Soaking in Aqueous Ammonia (SAA) Pretreatment of Whole Corn Kernels for Cellulosic Ethanol Production from the Fiber Fractions", Fermentation, 4(4), Article number: 87, 2018.

https://doi.org/10.3390/fermentation4040087

[22] Appeldoorn, M. M., de Waard, P., Kabel, M. A., Gruppen, H., Schols, H. A. "Enzyme resistant feruloylated xylooligomer analogues from thermochemically treated corn fiber contain large side chains, ethyl glycosides and novel sites of acetylation", Carbohydrate Research, 381, pp. 33-42, 2013. https://doi.org/10.1016/j.carres.2013.08.024

[23] Hagiwara, Y., Mihara, Y., Sakagami, K., Sagara, R., Bat-Erdene, U., Yatsunami, R., Nakamura, S. "Isolation of four xylanases capable of hydrolyzing corn fiber xylan from Paenibacillus sp. H2C", Bioscience, Biotechnology, and Biochemistry, 84(3), pp. 640-650, 2020. https://doi.org/10.1080/09168451.2019.1693253

[24] Grohmann, K., Bothast, R. J. "Saccharification of corn fibre by combined treatment with dilute sulphuric acid and enzymes", Process Biochemistry, 32(5), pp. 405-415, 1997. https://doi.org/10.1016/S0032-9592(96)00095-7

[25] Jacobsen, S. E., Wyman, C. E. "Cellulose and hemicellulose hydrolysis models for application to current and novel pretreatment processes", Applied Biochemistry and Biotechnology, 84, pp. 81-96, 2000. https://doi.org/10.1385/ABAB:84-86:1-9:81

[26] Kapu, N. S., Tranjano, H. L. "Review of hemicellulose hydrolysis in softwoods and bamboo", Biofuels, Bioproducts and Biorefining, 8(6), pp. 857-870, 2014. https://doi.org/10.1002/bbb.1517 
[27] Zhang, J., Wang, X., Chu, D., He, Y., Bao, J. "Dry pretreatment of lignocellulose with extremely low steam and water usage for bioethanol production", Bioresource Technology, 102(6), pp. 4480-4488. 2011.

https://doi.org/10.1016/j.biortech.2011.01.005

[28] Rana, V., Eckrad, A. D., Ahring, B. K. "Comparison of SHF and SSF of wet exploded corn stover and loblolly pine using in-house enzymes produced from $T$. reesei RUT C30 and A. saccharolyticus", Springerplus, 11(3), Article number: 516, 2014. https://doi.org/10.1186/2193-1801-3-516

[29] Paulova, L., Patakova, P., Branska, B., Rychtera, M., Melzoch, K. "Lignocellulosic ethanol: Technology design and its impact on process efficiency", Biotechnology Advances, 33(6), pp. 1091-1107, 2015. https://doi.org/10.1016/j.biotechadv.2014.12.002

[30] Tomás-Pejó, E., Oliva, J. M., Ballesteros, M., Olsson, L. "Comparison of SHF and SSF Processes From Steam-Exploded Wheat Straw for Ethanol Production by Xylose-Fermenting and Robust Glucose-Fermenting Saccharomyces cerevisiae Strains", Biotechnology and Bioengineering, 100(6), pp. 1122-1131, 2008. https://doi.org/10.1002/bit.21849

[31] Margono, M., Kaavessina, M., Khushairi Mohd Zahari, M. A., Hisyam, A. "Continuous Bioethanol Production Using Uncontrolled Process in a Laboratory Scale of Integrated Aerobic - Anaerobic Baffled Reactor", Periodica Polytechnica Chemical Engineering, 64(2), pp. 172-178, 2020. https://doi.org/10.3311/PPch.14653

[32] Philippidis, G. P., Smith, T. K. "Limiting Factors in the Simultaneous Saccharification and Fermentation Process for Conversion of Cellulosic Biomass to Fuel Ethanol", Applied Biochemistry and Biotechnology, 51, pp. 117-124, 1995.

[33] Binod, P., Janu, K. U., Sindhu, R., Pandey, A. "Chapter 10 Hydrolysis of Lignocellulosic Biomass for Bioethanol Production", In: Pandey, A., Larroche, C., Ricke, S. C., Dussap, C.-G., Gnansounou, E. (eds.) Biofuels: Alternative Feedstocks and Conversion Processes, Elsevier, Oxford, UK, 2011. https://doi.org/10.1016/B978-0-12-385099-7.00010-3

[34] Bedő, S., Fehér, A., Khunnonkwao, P., Jantama, K., Fehér, C. "Optimized Bioconversion of Xylose Derived from Pre-Treated Crop Residues into Xylitol by Using Candida boidinii", Agronomy, 11(1), Article number: 79, 2021. https://doi.org/10.3390/agronomy11010079

[35] Schirwitz, K., Schmidt, A., Lamzin, V. S. "High-resolution structures of formate dehydrogenase from Candida boidinii", Protein Science, 16(6), pp. 1146-1156, 2007. https://doi.org/10.1110/ps.062741707

[36] Weuster-botz, D., Paschold, H., Striegel, B., Gieren, H., Kula, M.-R., Wandrey, C. "Continuous Computer Controlled Production of Formate Dehydrogenase (FDH) and Isolation on a Pilot Scale", Chemical Engineering \& Technology, 17(2), pp. 131-137, 1994.

[37] Gonçalves, D. B., Batista, A. F., Rodrigues, M. Q. R. B., Nogueira, K. M. V, Santos, V. L. "Ethanol production from macaúba (Acrocomia aculeata) presscake hemicellulosic hydrolysate by Candida boidinii UFMG14", Bioresource Technology, 146, pp. 261-266, 2013.

https://doi.org/10.1016/j.biortech.2013.07.075
[38] Sluiter, A., Hames, B., Ruiz, R., Scarlata, C., Sluiter, J., Templeton, D., Crocker, D. "Determination of Structural Carbohydrates and Lignin in Biomass", Laboratory Analytical Procedure (LAP), Denver, CO, USA, Rep. NREL/TP-510-42618, 2012. [online] Available at: https://www. nrel.gov/docs/gen/fy13/42618.pdf [Accessed: 20 November 2020]

[39] Bhagia, S., Nunez, A., Wyman, C. E., Kumar, R. "Robustness of two-step acid hydrolysis procedure for composition analysis of poplar", Bioresource Technology, 216, pp. 1077-1082, 2016. https://doi.org/10.1016/j.biortech.2016.04.138

[40] Bura, R., Mansfiled, S. D., Saddler, J. N., Bothast, R. J. "SOCatalyzed Steam Explosion of Corn Fiber for Ethanol Production", Applied Biochemistry and Biotechnology, 98, pp. 59-72, 2002. https://doi.org/10.1385/ABAB:98-100:1-9:59

[41] Institutional Repository of Universidad Nacional "Novozymes cellulosic ethanol enyme kit. Enzymes for the hydrolysis of lignocellulosic materials", [online] Available at: https://repositorio. unal.edu.co/ [Accessed: 15 September 2020]

[42] Ghose, T. K. "Measurement of Cellulase Activities", Pure and Applied Chemistry, 59(2), pp. 257-268, 1987.

[43] Wood, T. M., Bhat, K. M. "Methods for Measuring Cellulase Activities", Methods in Enzymology, 160, pp. 87-110, 1988. https://doi.org/10.1016/0076-6879(88)60109-1

[44] Walther, T., Hensirisak, P., Agblevor, F. A. "The influence of aeration and hemicellulosic sugars on xylitol production by Candida tropicalis", Bioresource Technology, 76, pp. 213-220, 2001. https://doi.org/10.1016/S0960-8524(00)00113-9

[45] Gyalai-Korpos, M., Fehér, A., Barta, Z., Réczey, K. "Evaluation of an online fermentation monitoring system", Acta Alimentaria, 43(1), pp. 76-87, 2014. https://doi.org/10.1556/aalim.43.2014.1.8

[46] Van Eylen, D., van Dongen, F., Kabel, M., de Bont, J. "Corn fiber, cobs and stover: Enzyme-aided saccharification and co-fermentation after dilute acid pretreatment", Bioresource Technology, 102(10), pp. 5995-6004, 2011. https://doi.org/10.1016/j.biortech.2011.02.049

[47] Myat, L., Ryu, G.-H. "Characteristics of destarched corn fiber extrudates for ethanol production", Journal of Cereal Science, 60(2), pp. 289-296, 2014. https://doi.org/10.1016/j.jcs.2014.06.006

[48] Yoo, C. G., Nghiem, N. P., Kim, T. H. "Production of fermentable sugars from corn fiber using soaking in aqueous ammonia (SAA) pretreatment and fermentation to succinic acid using Escherichia coli AFP184", Korean Journal of Chemical Engineering, 33(10), pp. 2863-2868, 2016. https://doi.org/10.1007/s11814-016-0139-x

[49] Mussatto, S. I. (ed.) "Biomass Fractionation Technologies for a Lignocellulosic Feedstock Based Biorefinery", Elsevier, Amsterdam, Netherlands, 2016. https://doi.org/10.1016/C2014-0-01890-4

[50] Chaturvedi, V., Verma, P. "An overview of key pretreatment processes employed for bioconversion of lignocellulosic biomass into biofuels and value added products, 3 Biotech, 3, pp. 415-431, 2013. https://doi.org/10.1007/s13205-013-0167-8

[51] O'Brien, D. J., Senske, G. E., Kurantz, M. J., Craig, Jr, J. C. "Ethanol recovery from corn fiber hydrolysate fermentations by pervaporation", Bioresource Technology, 92, pp. 15-19, 2004. https://oi.org/10.1016/j.biortech.2003.08.003 